\title{
Philosophiques
}

\section{Liste des livres disponibles pour une recension}

Volume 47, numéro 1, printemps 2020

URI : https://id.erudit.org/iderudit/1070261ar

DOI : https://doi.org/10.7202/1070261ar

Aller au sommaire du numéro

Éditeur(s)

Société de philosophie du Québec

ISSN

0316-2923 (imprimé)

1492-1391 (numérique)

Découvrir la revue

Citer ce document

(2020). Liste des livres disponibles pour une recension. Philosophiques, 47(1),

247-248. https://doi.org/10.7202/1070261ar d'utilisation que vous pouvez consulter en ligne.

https://apropos.erudit.org/fr/usagers/politique-dutilisation/ 


\section{Liste des livres disponibles pour une recension}

Jean-François Aenishanslin, Les pensées parallèles. Husserl et Freud, Lausanne, Antipodes, 2019, 259 pages

"Au nom du peuple», revue Liaisons. Recherche partisane transocéanique, Mont réal, Sabotart, 20I8, 2I7 pages

Michel Bourdeau, Mary Pickering et Warren Schmaus (dir.), Love, Order, and Progress. The Science, Philosophy, and Politics of Auguste Comte, Pittsburgh, University of Pittsburgh Press, 2018, 4I6 pages

Serge Cantin, La distance et la mémoire. Essai d'interprétation de l'œuvre de Fernand Dumont, préface de J. Beauchemin, Québec, Presses de l'Université Laval, 2019, 392 pages

Yves Couture et Lawrence Olivier (dir.), Vers Deleuze. Nature, pensée, politique, Québec, Presses de l'Université Laval, 2018, 376 pages

Thomas De Koninck et Jean-François de Raymond, Beauté oblige. Écologie et dignité, Québec, Presses de l'Université Laval, 2018, 74 pages

Antoine Marie Guy d'Oliveira, Identité, horizon moral, interculturalité. Charles Taylor face aux défis (post) modernes de l'humain, Paris, Les Éditions du Cerf, 2OI8, 42I pages

Daniel Desroches, La philosophie comme mode de vie, $2^{\mathrm{e}}$ éd., Québec, Presses de l'Université Laval, 2019, 465 pages

Thomas Dommange, Le rapt ontologique: penser l'être des singularités, Montréal, Éditions Nota Bene, 2019, 259 pages

François Duchesneau, Organisme et corps organique de Leibniz à Kant, Paris, Vrin, 20I8, 522 pages

Guillaume Fagniez, Comprendre l'historicité. Heidegger et Dilthey, Paris, Hermann, 2019, 468 pages

Simon Gallegos Gabilondo, Les mondes du voyageur. Une épistémologie de l'exploration (XVI $I^{e}$ XVIII siècle), Paris, Éditions de la Sorbonne, 20I 8, 384 pages

Jean-Luc Gouin, Hegel. De la Logophonie comme chant du signe, Québec, Presses de l'Université Laval, 2018, 3 I 2 pages

Sylvaine Gourdain, Sortir du transcendantal. Heidegger et sa lecture de Schelling, Bruxelles, Ousia, 201 8, 322 pages

Caroline Gravel, L'amour virtuel, un amour véritable?, Québec, Presses de l'Université Laval, 2019, 229 pages

Jean Grondin, La beauté de la métaphysique: essai sur les piliers herméneutiques, Paris, Éditions du Cerf, 2019, I92 pages

Pierre Guenancia, La voie de la conscience: Husserl, Sartre, Merleau-Ponty, Ricour, Paris, Presses universitaires de France, 2018, 237 pages

Marco Jean, Penser la lä̈cité avec Habermas. La place et le rôle de la religion dans la démocratie selon Jürgen Habermas, Québec, Presses de l'Université Laval, 20I9, 3 IO pages

Vincent Legeay, L'essence plastique. Aptitudes et accommodements chez Spinoza, Paris, Éditions de la Sorbonne, 20I 8, I 40 pages

Alice Le Goff, Pragmatisme et démocratie radicale, Paris, CNRS éditions, 2019, 272 pages 
Adrien, Louis, Leo Strauss, philosophe politique, Paris, CNRS éditions, 20I9, 35 I pages

Gilles Marmasse et Roberta Picardi (dir.), Ricour et la pensée allemande. De Kant à Dilthey, Paris, CNRS Éditions, 2019, 296 pages

Johann Michel, La fabrique des sciences sociales. D’Auguste Comte à Michel Foucault, Paris, Presses universitaires de France, 201 8, 206 pages

Richard Popkin, Histoire du scepticisme. De la fin du Moyen-Âge à l'aube du XIX $X^{e}$ siècle, trad. Benoît Gaultier, Marseille, Agone, 20I9, 9I 2 pages

Dominique Pradelle et Julien Farges (dir.), Husserl: Phénoménologie et fondements des sciences, Paris, Hermann, 20I9, 5 I I pages

Olivier Sartenaer, Qu'est-ce que l'émergence?, Paris, Librairie philosophique Vrin, 20I 8 , I 26 pages

Michel Seymour et Jérôme Gosselin-Tapp, La nation pluraliste: repenser la diversité religieuse an Québec, Montréal, Presses de l'Université de Montréal, 2018, 293 pages

Quentin Skinner, Visions politiques. Sur la méthode, vol. I, trad. Christopher Hamel, Genève, Librairie Droz, 2018, 27I pages

Thomas Skorucak, Le courage des gouvernés. Michel Foucault et Hannah Arendt, Paris, CNRS éditions, 20I9, 378 pages 